\title{
Is silt the most influential soil grain size fraction?
}

Article

Accepted Version

Parry, S. P., Hodson, M. E., Oelkers, E. H. and Kemp, S. J. (2011) Is silt the most influential soil grain size fraction? Applied Geochemistry, 26 (Supple). S119-S122. ISSN 08832927 doi: https://doi.org/10.1016/j.apgeochem.2011.03.045 Available at https://centaur.reading.ac.uk/20340/

It is advisable to refer to the publisher's version if you intend to cite from the work. See Guidance on citing.

To link to this article DOI: http://dx.doi.org/10.1016/j.apgeochem.2011.03.045

Publisher: Elsevier

All outputs in CentAUR are protected by Intellectual Property Rights law, including copyright law. Copyright and IPR is retained by the creators or other copyright holders. Terms and conditions for use of this material are defined in the End User Agreement.

\section{www.reading.ac.uk/centaur}

\section{CentAUR}

Central Archive at the University of Reading

Reading's research outputs online 


\section{Is silt the most influential soil grain size fraction?}

S. A. Parry ${ }^{a^{a}}$, M. E. Hodson ${ }^{a}$, E. H. Oelkers ${ }^{\text {b }}$, S. J. Kemp ${ }^{c}$

${ }^{a}$ Soil Research Centre, Dept. Geography and Environmental Science, School of Human and Environmental Sciences, University of Reading, RG6 6DW, UK. s.a.parry@reading.ac.uk*, m.e.hodson@reading.ac.uk, +44 (0)118 3788911.

b LMTG, Université Paul Sabatier/CNRS-UMR 5563, 31400 Toulouse, France. oelkers@Imtg.obs-mip.fr.

${ }^{\mathrm{C} B r i t i s h}$ Geological Survey, Keyworth, Nottingham, NG12 5GG, UK. sjk@bgs.ac.uk.

\section{Abstract}

The contribution of individual grain size fractions (2000-500, 500-250, 250-63, 63-2 and $<2 \mu \mathrm{m}$ ) to bulk soil surface area and reactivity is discussed with reference to mineralogical and oxalate and dithionite extractions data. The $63-2 \mu \mathrm{m}$ fraction contributed up to 56 and $67 \%$ of bulk soil volume and BET surface area respectively. Consideration of these observations and the mineralogy of this fraction suggest that the $63-2 \mu \mathrm{m}$ fraction may be the most influential for release of elements via mineral dissolution in the bulk soil.

Keywords: grain size, surface area, volume fraction, mineralogy, surface coatings.

\section{Introduction}

The surface area of soil grains impacts on both availability of surfaces for dissolution and element release and availability of surfaces for sorption (c.f. Oelkers et al., 2009; Gherbi et al., 2010). Understanding the variability and evolution of mineral surface area in soils is therefore crucial for modelling the evolution of soils. White et al (1996) and Hodson (2002) showed that the specific surface area of soil minerals increases with decreasing grain size. For a constant mineralogy and even distribution of reactive sites this implies that as minerals break down into smaller grains, a soil's surface area and thus reactivity should increase. However a soil's mineralogy can vary with grain size and typically the mass of mineral material present decreases with decreasing grain size. Therefore the increase in mineral specific surface area with decreasing grain size is not necessarily associated with an increase in soil reactivity. The aim of this study is to examine how the specific surface area of grain size fractions and their parent bulk soil vary in conjunction with mineralogy and particle size distribution by depth.

\section{Materials and Method}

Soil was sampled (using a coarse-stepped continuous strategy deliminated by the median depth) by depth $(6.5,19.5,32.5,45.5,58.5,71.5$ and $89 \mathrm{~cm}$ depth) from a granitic podzol directly overlying the Dartmoor Massif in Princetown, UK. An alluviation (Bs) horizon was present between $27-42 \mathrm{~cm}$ depth, and is contained within the 32.5 and $45.5 \mathrm{~cm}$ samples. Soil was air-dried, dry sieved to $<2 \mathrm{~mm}$, and soil organic matter was removed using sodium hypochlorite. Dry sieving and sedimentation was used to produce the 2000-500, 500-250, 
250-63, 63-2 and $<2 \mu \mathrm{m}$ size fractions. Amorphous and free iron oxides were removed using oxalate (amorphous only) and dithionite extractions.

Soil particle size distribution (PSD) (as percent by volume) was determined by dry sieving and laser granulometry. Soil mineralogy was determined by $\mathrm{X}$-ray diffraction, and quantified using Rietveld refinement. Soil specific surface area (SSA) was determined using the BET isotherm and nitrogen gas adsorption, and calculated geometrically from PSD data with the assumption that particles were smooth spheres with a density of $2.65 \mathrm{~g} \mathrm{~cm}^{-3}$. Geometric SSA of individual size fractions was calculated using the distribution of particle sizes within each fraction from the Bulk (i.e., bulk mineral soil) PSD data. The roughness factor $(\lambda)$ was calculated as the ratio of BET to Geometric SSA.

\section{Results}

The 2000-500 and 63-2 $\mu \mathrm{m}$ fractions represented the majority of soil particles by volume (Figures 1 and 2). These fractions contained a large proportion of the quartz and Kfeldspar in the Bulk. The $63-2 \mu \mathrm{m}$ fraction also contained the majority of the plagioclase feldspar and a large proportion of the micas and clays.

The trends in geometric SSA, BET SSA, and $\lambda$ with depth for the bulk and size fractions are shown in Figure 3. Bulk geometric SSA varied over several orders of magnitude compared to a maximum factor of 33 for the BET SSA. The BET SSA of the $<2 \mu \mathrm{m}$ fraction was considerably greater than other fractions in the mid and lower profile. From the bedrock to the soil surface the BET SSA and $\lambda$ of the $2000-500,500-250$ and $<2 \mu \mathrm{m}$ fractions decreased, but the $250-63$ and $63-2 \mu \mathrm{m}$ fractions peaked at $45.5 \mathrm{~cm}$ depth. The Bulk geometric SSA, BET SSA, and $\lambda$ were most comparable to those of the $63-2 \mu \mathrm{m}$ fraction.

The trends in the contribution of individual grain size fractions to Bulk geometric and BET surface area are shown by Figures $4 A$ and $B$. The proportion of total bulk BET surface area due to the $63-2 \mu \mathrm{m}$ fraction peaked at $45.5 \mathrm{~cm}$. The $<2 \mu \mathrm{m}$ fraction (circled) contributed a disproportionally large percent of bulk geometric surface area relative to bulk BET when compared to other size fractions (Figure $4 \mathrm{C}$ ).

A decrease in the relative proportion of fine-grained material in the Bulk, and, thus, Bulk geometric SSA was observed in the top $19.5 \mathrm{~cm}$ following dithionite and oxalate extractions (Figure $5 \mathrm{~A}$ ). In the top $6.5 \mathrm{~cm}$ the dithionite extraction decreased the Bulk geometric SSA by a greater percentage than oxalate. Following these extractions the Bulk BET SSA decreased in the top $32.5 \mathrm{~cm}$ and increased at $67.5 \mathrm{~cm}$ depth (Figure 5B). The Bulk BET SSA values for the post dithionite samples were equal to or less than for oxalate.

Following the oxalate and dithionite extractions the proportion of Bulk geometric surface area in the upper profile represented by the $<2,63-2$ and $250-63 \mu \mathrm{m}$ (dithionite only) fractions decreased and for the 500-250, and 2000-500 $\mu \mathrm{m}$ ( $6.5 \mathrm{~cm}$ only) fractions increased

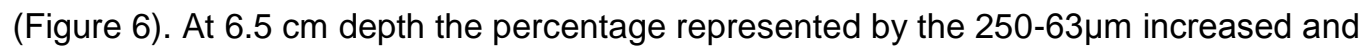
decreased post oxalate and dithionite extraction respectively. 


\section{Discussion}

The 63-2 $\mu \mathrm{m}$ fraction dominates the Bulk mineralogy and surface area of the studied soils. It had the greatest volume fraction (Figure 1), and contained the majority of plagioclase, and substantial amounts of micas and clays (Figure 2). Only the $<2 \mu \mathrm{m}$ fraction had a greater geometric and BET SSA (Figures $3 \mathrm{~A}$ and $\mathrm{B}$ ), but once expressed as a percentage of Bulk BET surface area the $63-2 \mu \mathrm{m}$ fraction is more significant (Figure 4B). This finding agrees with those findings of Hodson (2002) that suggested that the release of elements from the dissolution of the $53-2 \mu \mathrm{m}$ fraction (derived from the B horizon of a podzol developed over granitic till) could be the most important despite its low mass fraction. The 2000-500 and $<2 \mu \mathrm{m}$ fractions appear to be less influential on the Bulk than the $63-2 \mu \mathrm{m}$ but exhibit similar overall contributions. They contributed comparable proportions of the Bulk BET surface area (Figure 4B) due to the large volume fraction of the 2000-500 and large BET $\mathrm{SSA}$ of the $<2 \mu \mathrm{m}$ fractions (Figures 1 and $3 \mathrm{~B}$ ). Mineralogical differences make it unclear whether BET SSA would dominate over volume fraction in terms of their contribution to Bulk elemental release rates (Figure 2). The remaining sand fractions had a similar mineralogy but the volume fraction and BET SSA of the $250-63 \mu \mathrm{m}$ fraction was greater, suggesting that it

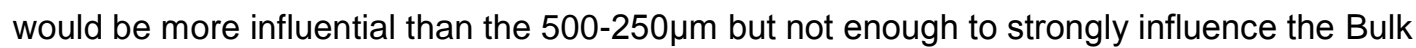
(Figures 2 and 3B).

The removal of fine-grained amorphous and free iron oxide phases from the upper profile caused a decrease in Bulk geometric SSA (Figure 5A). The absence of a residual increase in the geometric SSA of the $2000-500 \mu \mathrm{m}$ fraction following the oxalate extraction suggests the presence of coarse aggregates that are cemented by an amorphous phase. The decrease in Bulk BET SSA in the top $19.5 \mathrm{~cm}$ following the extractions coincided with a decrease in Bulk geometric SSA, and thus the removal of fine particles (Figure 5A and B).

At the $32.5 \mathrm{~cm}$ depth, Bulk BET SSA decreased more significantly with the dithionite than the oxalate extraction; there was no accompanying decrease in Bulk geometric SSA. This finding suggests that the decrease in Bulk BET SSA was due to the removal of predominantly free iron oxide based surface coatings with an elaborate and potentially porous structure that contributed directly towards the Bulk BET SSA. In a stratigraphical context this relates to the translocation of $\mathrm{Al}$ and Fe sesquioxides from overlying horizons to the $\mathrm{Bs}$ horizon at this depth. The BET SSA of the $250-63$, $<2$, and $63-2 \mu \mathrm{m}$ fractions peaked at $45.5 \mathrm{~cm}$ depth (Figure $3 \mathrm{~B}$ ) and all three fractions contained free iron oxides at $32.5 \mathrm{~cm}$ depth (extraction data, not shown here). As the geometric SSA of these fractions does not increase following the extractions this suggests that the free iron oxides are probably present as surface coatings on the grains rather than as discrete particles. However, it is not clear whether such coatings would affect the reactivity of the underlying minerals or the release of elements due to dissolution.

Bulk BET SSA increased following the extractions without a corresponding increase in Bulk geometric SSA at $67.5 \mathrm{~cm}$ depth. This suggests that at this depth coatings decrease 
the Bulk BET SSA by smoothing over and cementing together more complex, higher surface area mineral grains and surface features. Both the oxalate and dithionite extractions remove amorphous $\mathrm{Fe}, \mathrm{Al}, \mathrm{Si}$ and $\mathrm{Mn}$ phases with the dithionite also removing free iron oxides.

Differences in the Bulk SSA after the two extractions suggest that the free iron oxides contribute to surface area via porous coatings and complex architecture as in the $32.5 \mathrm{~cm}$ samples while the amorphous material removes surface area by smoothing out topography and that more surface area is removed by the amorphous coatings than is provided by the free iron oxides. Unfortunately we cannot determine in which size fraction(s) these amorphous coatings are located.

Assuming that soil particles are spheres (or regular shapes) in geometric surface area calculations overstates the importance of the $<2 \mu \mathrm{m}$ fraction (Figures $3 \mathrm{~A}$ and $4 \mathrm{~A}$ ). This is illustrated by the low $\lambda$ value for the $<2 \mu \mathrm{m}$ fraction despite its high BET SSA, and the high ratio between this fraction's contribution towards Bulk geometric and BET surface area

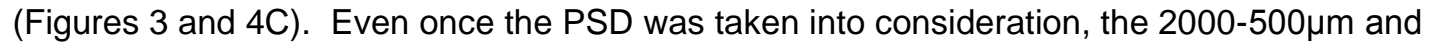
$63-2 \mu \mathrm{m}$ fractions were still underrepresented considering their contributions to Bulk BET surface area and, potentially, elemental release rates (Figures 4A and B). Geometric surface area calculations can take the shape of individual particles into account using density and shape factors, as discussed by Hodson (1998; 2006). Without such provision, it appears that geometric surface areas are a poor representation of the true surface areas of minerals in soils. Furthermore, BET SSA is not necessarily representative of reactive mineral surface area either, because the presence of un-reactive amorphous and free iron oxide phases can affect this surface area to varying degrees. The distribution of such un-reactive phases should be considered when using BET SSA as a normalising term.

\section{Conclusions}

Despite the presence of free iron oxide surface coatings, we suggest that the $63-2 \mu \mathrm{m}$ size fraction is the most important in terms of Bulk BET surface area and, potentially, Bulk elemental release rates. The $2000-500$ and $<2 \mu \mathrm{m}$ fractions contributed less than the $63-2 \mu \mathrm{m}$

fraction to Bulk BET surface area. However, their mineralogy and the presence of un-reactive phases make it unclear which size fraction would contribute more to Bulk elemental release via dissolution. Even though the investigation of individual grain size fractions provides further data on the source of a soil's surface area and potential elemental release rates, our surface area data suggests that the study of the Bulk is still generally appropriate. This is due to the fact that the $63-2 \mu \mathrm{m}$ fraction is not only the most important, but the most representative and thus the best represented by the Bulk.

A dissolution study investigating the contribution of the discussed grain size fractions to bulk soil elemental release rates is currently ongoing.

\section{Acknowledgements}


We would like to gratefully acknowledge The University of Reading, NERC, The British

Geological Survey, and MIR-EST (MEST-CT-2005-021120) for their funding and support.

\section{References}

Gherbi, C., Bouabsa, L. \& Oelkers E.H. (2010) An experimental study of lake-water-sediment interaction rates. Comptes Rendu Geosci., 342(2), 126-135.

Hodson, M. E., Langan, S. J. \& Meriau, S. (1998) Determination of mineral surface area in relation to the calculation of weathering rates. Geoderma, 83(1-2), 35-54.

Hodson, M. E. (2002) Variation in element release rate from different mineral size fractions from the b horizon of a granitic podzol. Chem. Geol., 190 (1-4), 91-112.

Hodson, M. E. (2006) Does reactive surface area depend on grain size? Results from ph 3 , $25{ }^{\circ} \mathrm{C}$ far-from-equilibrium flow-through dissolution experiments on anorthite and biotite. Geochimica et Cosmochimica Acta, 70(7), 1655-1667.

Oelkers, E.H., Golubev, S.V., Chairat, C., Pokrovsky, O.S. \& Schott, J. (2009) The surface chemistry of multi-oxide silicates. Geochim. Cosmochim. Acta., 73(16), 4617-4634.

White, A. F., Blum, A. E., Schulz, M. S., Bullen, T. D., Harden, J. W. \& Peterson, M. L. (1996) Chemical weathering rates of a soil chronosequence on granitic alluvium: I.

Quantification of mineralogical and surface area changes and calculation of primary silicate reaction rates. Geochim. Cosmochim. Acta, 60(14), 2533-2550.

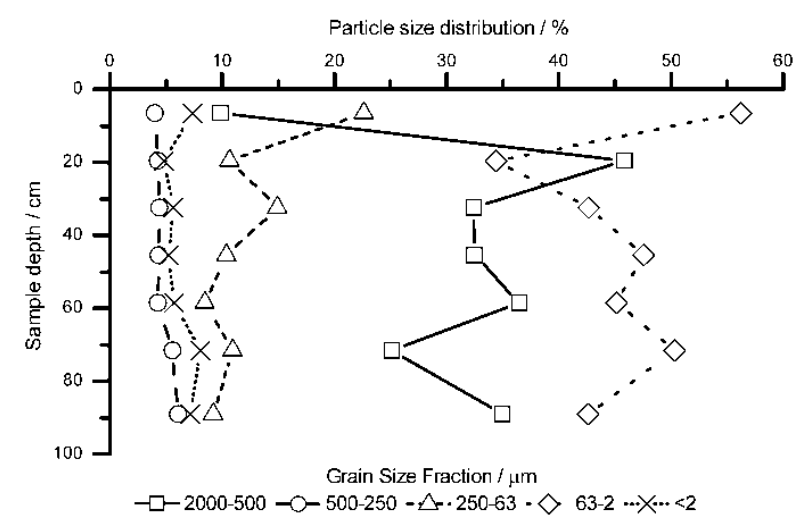

Figure 1. Bulk mineral soil particle size distribution by volume. 


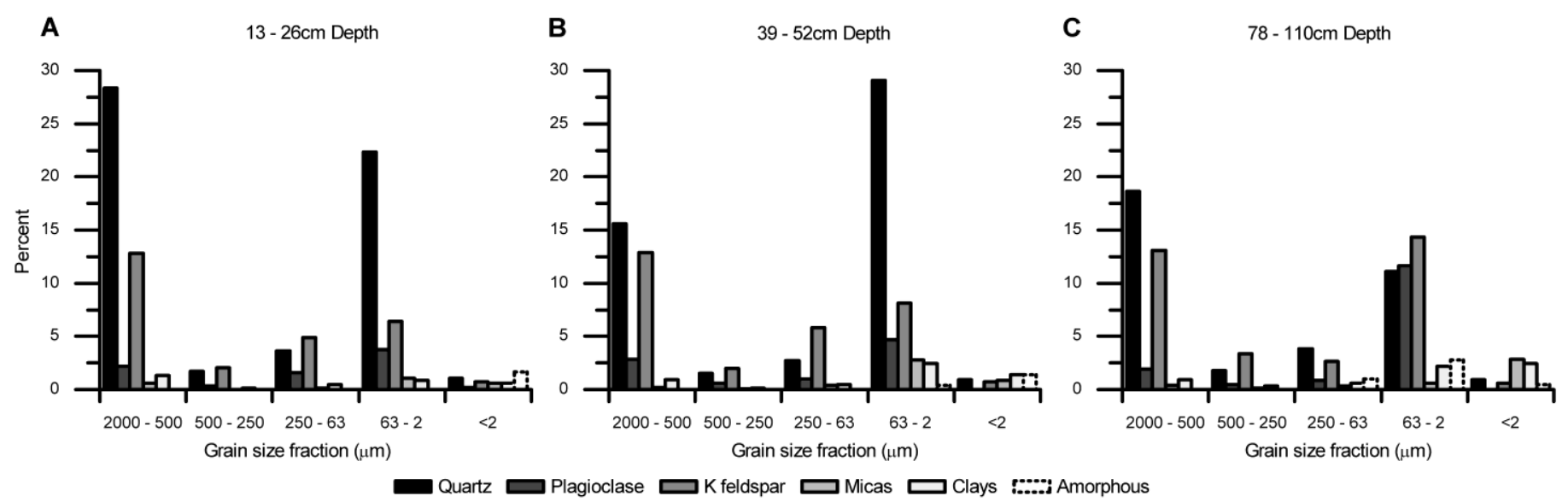

Figure 2. Soil mineral distribution across grain size fractions expressed in terms of percentage of bulk soil mineralogy. Calculated using the following: percentage by mass of mineral present in the size fraction $x$ percentage by volume of the size fraction present in the Bulk $/ 100$. Minerals contained under group headings are: plagioclase $=$ albite and anorthite; K-feldspar = microcline and sanidine $;$ micas = muscovite and biotite; and clays = kaolinite, chlorite and montmorillonite.

A

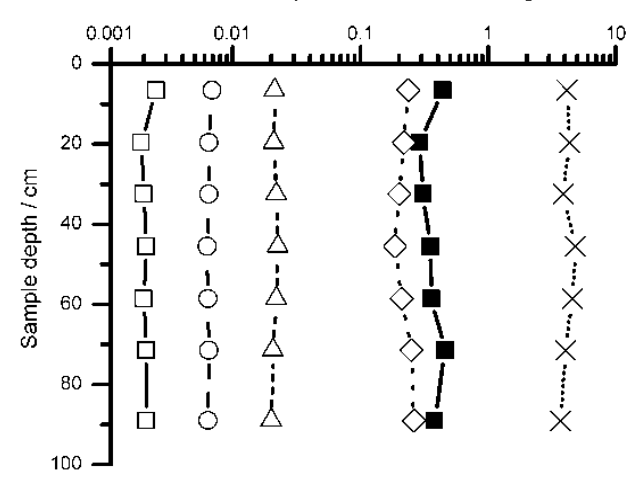

B

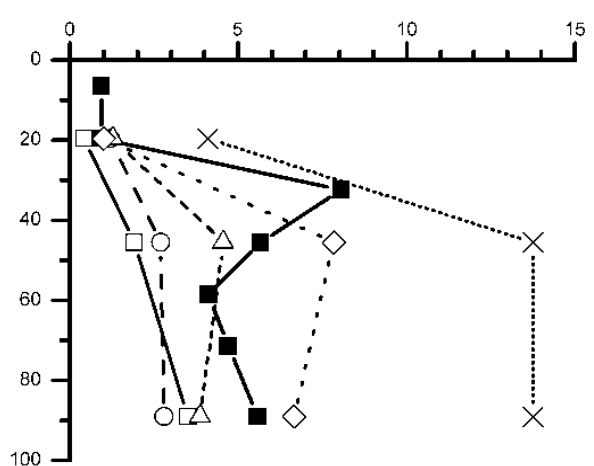

C

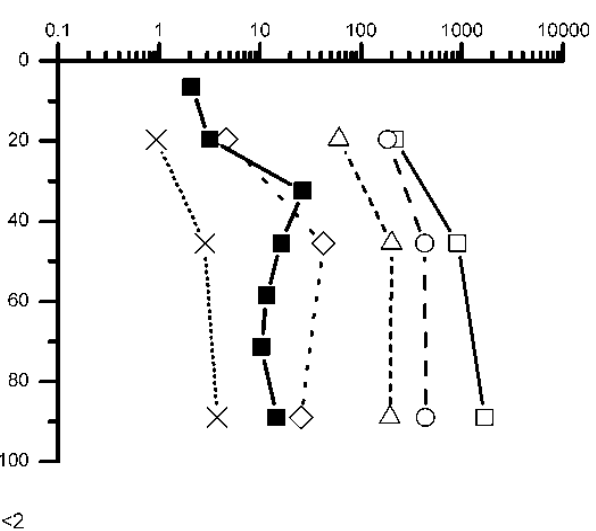

Figure 3. Geometric (A) and BET specific surface area $(B)$ and the roughness factor $(C)$ of the bulk mineral soil and size fractions.

A

Proportion of bulk soil Geometric surface area

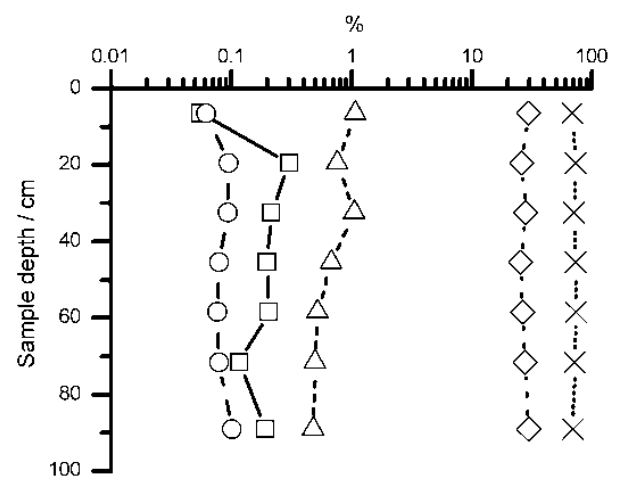

B

Proportion of bulk soil BET surface area

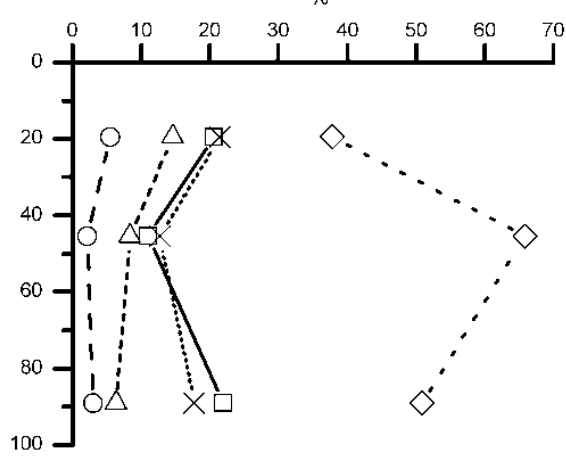

Grain Size Fraction / $\mu \mathrm{m}$
C Proportion of bulk soil BET vs Geometric Proporiton of bulk soil Geometric surface area / \%

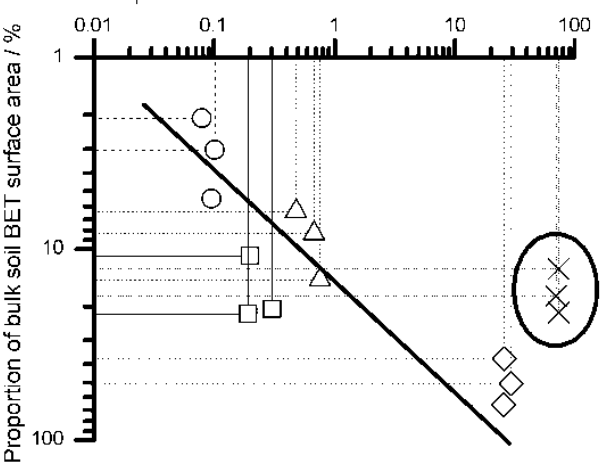

$-\square-2000-500 \frown-500-250-\_\cdot 250-63 \cdot \diamond 63-2 \cdots \times \cdots<2$

Figure 4. Percentage of bulk mineral soil surface area due to different size fractions for $(A)$ geometric and (B) BET surface area, and the proportion of bulk mineral geometric surface area against the proportion of bulk mineral BET surface area $(C)$. Calculated using the 
following: size fraction BET SSA $x$ percentage by volume of size fraction in Bulk / Bulk BET SSA.

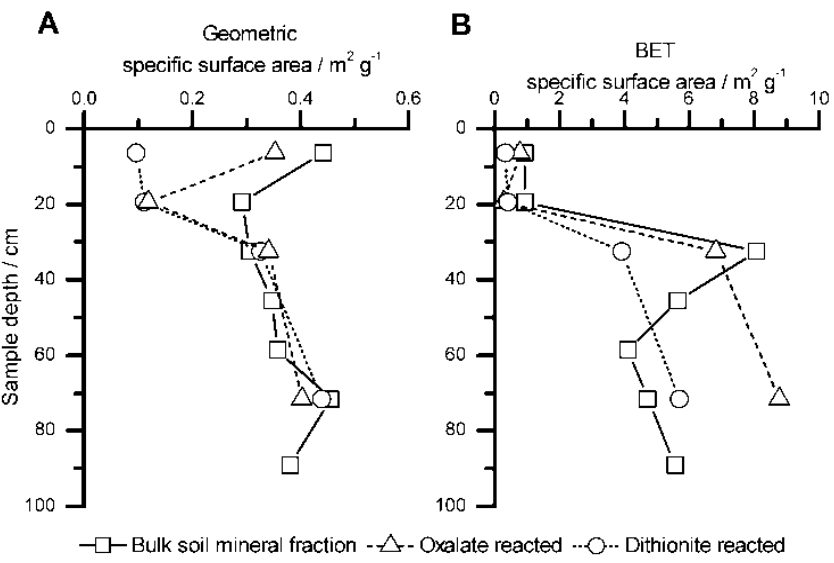

Figure 5. Bulk mineral soil geometric (A) and BET (B) specific surface area prior to and following oxalate and dithionite extractions.
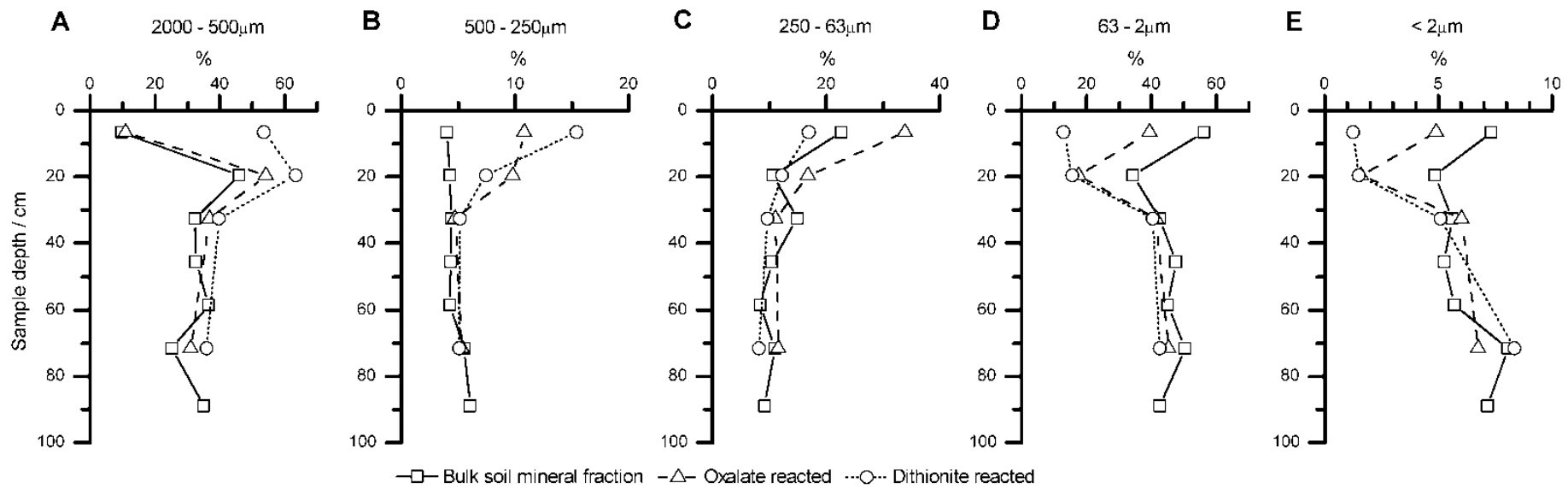

Figure 6. Percentage of bulk mineral soil geometric surface area due to different size fractions prior to and following oxalate and dithionite extractions. 